\title{
Conical expansion of the outer subventricular zone and the role of neocortical folding in evolution and development
}

\author{
Eric Lewitus, Iva Kelava and Wieland B. Huttner* \\ Max Planck Institute of Molecular Cell Biology and Genetics, Dresden, Germany
}

\section{Edited by:}

Roberto Lent, Federal University of Rio de Janeiro, Brazil

Reviewed by:

Juan A. De Carlos, Instituto Cajal

(Consejo Superior de

Investigaciones Científicas), Spain

Jon H. Kaas, Vanderbilt University,

USA

Charles F. Stevens, The Salk

Institute for Biological Studies, USA

${ }^{*}$ Correspondence:

Wieland B. Huttner, Max Planck Institute of Molecular Cell Biology and Genetics, Pfotenhauerstr. 108, 01307 Dresden, Germany

e-mail: huttner@mpi-cbg.de
There is a basic rule to mammalian neocortical expansion: as it expands, so does it fold. The degree to which it folds, however, cannot strictly be attributed to its expansion. Across species, cortical volume does not keep pace with cortical surface area, but rather folds appear more rapidly than expected. As a result, larger brains quickly become disproportionately more convoluted than smaller brains. Both the absence (lissencephaly) and presence (gyrencephaly) of cortical folds is observed in all mammalian orders and, while there is likely some phylogenetic signature to the evolutionary appearance of gyri and sulci, there are undoubtedly universal trends to the acquisition of folds in an expanding neocortex. Whether these trends are governed by conical expansion of neocortical germinal zones, the distribution of cortical connectivity, or a combination of growth- and connectivity-driven forces remains an open question. But the importance of cortical folding for evolution of the uniquely mammalian neocortex, as well as for the incidence of neuropathologies in humans, is undisputed. In this hypothesis and theory article, we will summarize the development of cortical folds in the neocortex, consider the relative influence of growth- vs. connectivity-driven forces for the acquisition of cortical folds between and within species, assess the genetic, cell-biological, and mechanistic implications for neocortical expansion, and discuss the significance of these implications for human evolution, development, and disease. We will argue that evolutionary increases in the density of neuron production, achieved via maintenance of a basal proliferative niche in the neocortical germinal zones, drive the conical migration of neurons toward the cortical surface and ultimately lead to the establishment of cortical folds in large-brained mammal species.

Keywords: neocortex, gyrencephaly, subventricular zone, neural progenitors, mammals, extracellular matrix, phylogenetics

\section{INTRODUCTION}

Cortical folding and brain development are tightly linked. The prenatal characterization of gyri and sulci may be used to identify functionally distinct cortical areas in many species and predict normal or pathological cerebral function at term. Close correlations between cortical morphology and behavioral function (or dysfunction) suggest that the early development of cortical folds constitutes an important step, either for normal development or as an indicator of normal development, in the construction of the human brain. Comparisons between normal and pathological human brains and between humans and other mammal species highlight important differences in progenitor cell-type abundances, cell-cycle dynamics, radial fiber organization, and gene expression profiles that account for gross phenotypic differences in neocortical morphology and function and even organismal behavior (Bayer and Altman, 1991; Beaulieu, 1993; Dehay et al., 1993; Polleux et al., 1997a,b; Lukaszewicz et al., 2005; Dubois et al., 2008; Toro et al., 2008; Clowry et al., 2010; Fietz et al., 2010, 2012; Hansen et al., 2010; Zilles et al., 2013).

\section{THE CHRONOLOGY OF NEOCORTICAL FOLDING DURING DEVELOPMENT IS HIGHLY REGULATED AND CONSERVED ACROSS SPECIES}

The emergence of neocortical gyri and sulci can be summarized in two stages: (1) the demarcation of primary gyri at human gestation weeks (GW) 23-31; and (2) the emergence of secondary gyri and the growth of sulcal length and depth between late stages of fetal development and early stages of postnatal life (Figure 1) (Chi et al., 1977; Armstrong et al., 1995; Mayhew et al., 1996). Stage 1, which follows the demarcation of cerebral lobes and limbic cortical gyri, is largely conserved between humans and other gyrencephalic primates. The correlative increase in cerebral volume and gyrification during this stage, including a dramatic increase in gyri in the occipital region, may in fact constitute the formation of a characteristic pattern of gyrencephaly common to all gyrencephalic primates. Work in Old World monkeys has shown that all neocortical gyri, with the exception of the superior temporal gyrus, emerge during Stage 1 and that both the chronology of emergence and rostrocaudal distribution of gyri are homologous in monkeys and humans (Zilles 


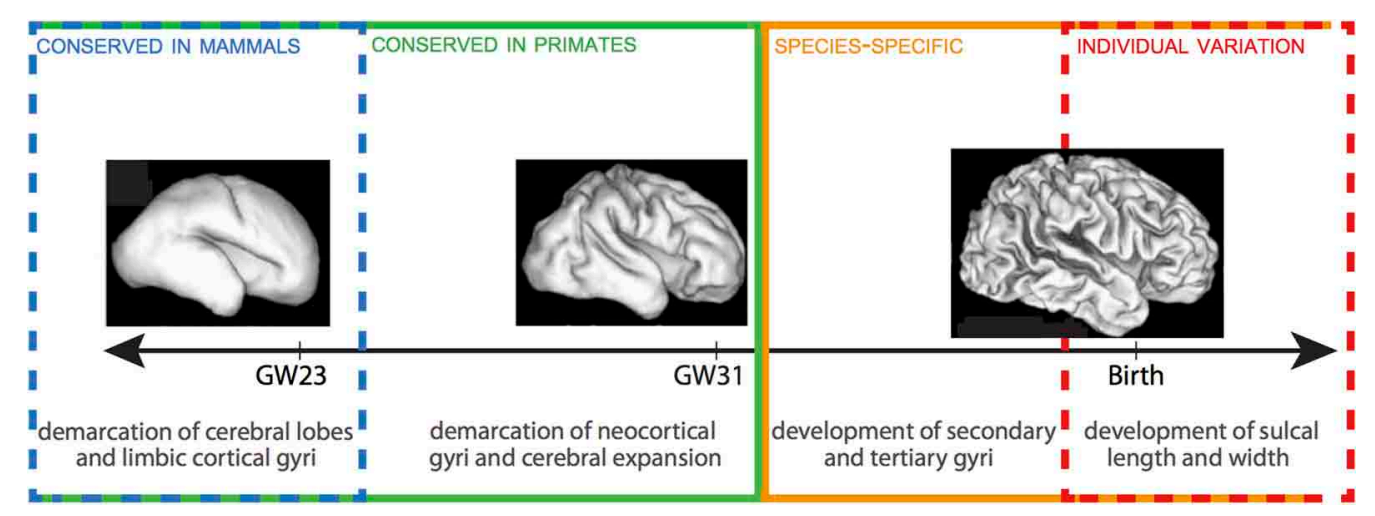

FIGURE 1| Timeline of gyrification in human. Stages 1 and 2 are delineated by GW 31-32. There is a progressive lack of conservation in cortical folding patterns toward the final stages of gyrification, as minor developmental changes in gyri and sulci become increasingly specialized to species and, ultimately, susceptible to local environmental and experiential variations. 3D reconstructions of fetal human brains from Barnette et al. (2009). Figure follows Sawada et al. (2012b). et al., 1988; Rilling and Insel, 1999; Sawada et al., 2012a,b). There is, despite this broad conservation, a delayed emergence of the parietoccipital gyri (e.g., cuneus, angular gyrus, supramarginal gyrus) in humans compared to monkeys, which, because these gyri are associated with Wernicke's area in humans but dorsal extrastriate cortex in monkeys (Sawada et al., 2012a,b), may indicate that heterochronic changes in gyri emergence reflect species-specific adaptations in particular cortical regions.

Across all mammal species, cortical folds accumulate nonlinearly with increasing brain volume, such that, per gram, larger brains are more gyrencephalic than smaller brains (Zilles et al., 2013). Within species, gyrencephaly index (GI) shows high levels of heritability, but is negatively correlated with both cerebral volume and surface area (Rogers et al., 2010). The positive correlation between GI and cerebral volume and surface observed across species is, therefore, unlikely to come from a common set of genes. Certain human pathologies further demonstrate that genetic mutations affecting gyrencephaly may have limited effect on cerebral volume (e.g., lissencephaly, polymicrogyria) or cerebral volume on gyrencephaly (e.g., microcephaly, megalencephaly). The second stage of gyrification in humans is marked by the prenatal emergence of small sulci and dimples-generated independently of cerebral gyri and accompanied by a major increase in brain weight-and the postnatal growth of sulcal length and depth (Sawada et al., 2012a). Unlike Stage 1, this stage is not correlated with increases in cerebral volume. Rather, patterns in monkeys showing considerable increases in sulcal infolding in the occipital region and secondary and tertiary sulci formation in the frontoparietal region indicate that this period may define species-specific topography of gyri (Fukunishi et al., 2006; Kashima et al., 2008; Sawada et al., 2010, 2012a). For example, increased sulcal infolding in the frontal region of humans (Dubois et al., 2008) compared to macaques (Sawada et al., 2010) underscores the numerous human-specific adaptations to the prefrontal cortex (e.g., Sherwood et al., 2006; Bianchi et al., 2012); and disproportionate inter-indiviual variation in humans in the anterior prefrontal cortex further underscores the phylogenetic recentness and plasticity of this region (Huttner et al., 2005). The terminus of gyrencephaly, too, shows species-specificity: degree of gyrencephaly stabilizes in baboons around birth (Kochunov et al., 2010), while in macaques and humans it reaches a maximum around 1 year after birth (Sawada et al., 2012a). The wideranging conservation of gyrencephalic patterning, which cannot be explained simply as a physiological consequence of neocortical expansion, suggests that genetic mechanisms play an importantalbeit likely indirect-role in the specification of cortical folding (Rakic, 1988). These genes may either programmatically shape the topology of germinal zones during cortical growth to anticipate gyral and sulcal formation (Smart and McSherry, 1986; Régis et al., 2005) or specify patterns of fiber connectivity to differentially effect tension at the developing cortex (Van Essen, 1997; Hilgetag and Barbas, 2006). The high heritability of earlyforming gyri, as well as the species-specific distribution of lateforming sulci, support a scenario in which gyrencephalic tinkering may be accomplished through selection on axonal tension, but that establishment of primary gyri is determined by ventricular (VZ) and subventricular zone (SVZ) organization during cortical development.

\section{SUBVENTRICULAR EXPANSION AND THE ESTABLISHMENT OF GYRI}

The emergence of new structures is typically limited to selection on existing developmental pathways. Minor perturbations in timing or cell-type proportions may result in major phenotypic adaptations (e.g., delayed retinal neurogenesis in nocturnal vs. diurnal monkeys or the preponderance of basal or apical neurogenesis in larger- and smaller-brained species). Notwithstanding, there are quite divergent developmental pathways able to generate nearly identical phenotypes (e.g., gastrulation, neural crest formation, and germ cell formation). But in either case, we may assume that selection at the gross morphological level is complemented by adaptations in developmental processes. Therefore, any understanding of the appearance and distribution of cortical folds must be gleaned from a comparison of neural progenitors during development across taxa (Figure 2). 


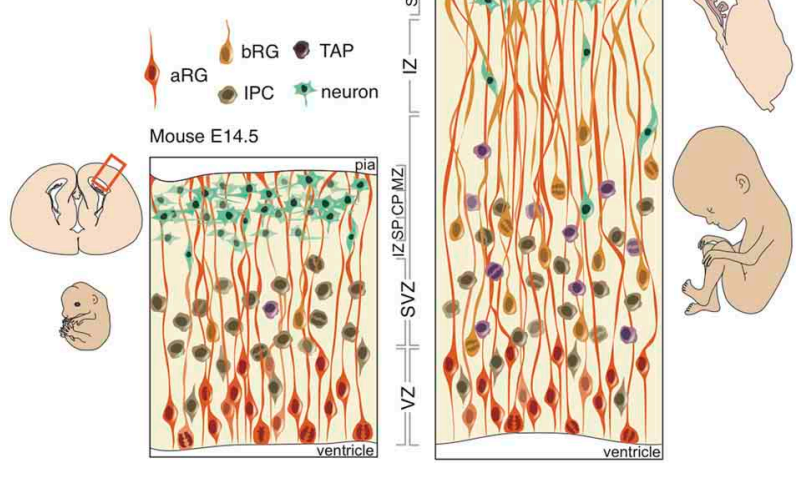

FIGURE 2 | Schematic of neural progenitors in the developing neocortex in mouse (left) and human (right). Polarized progenitors (bRG and $\mathrm{aRG}$ ) are depicted with processes extending to the apical (bottom) and/or basal (top) surface. Non-polarized cells (IPCs and TAPS) divide exclusively in the SVZ in both mouse and human. The human SVZ is relatively expanded compared to the mouse and divided into an outer (OSVZ) and inner (ISVZ) region. CP, cortical plate; IZ, intermediate zone; MZ, marginal zone; SP, subplate.

At the onset of neurogenesis, neuroepithelial cells forming a pseudo-stratified epithelium divide rapidly and symmetrically, thus expanding the progenitor pool that will directly or indirectly generate all of the excitatory neurons in the neocortex. As neurogenesis proceeds and the epithelium thickens, neuroepithelial cells, while retaining their apical and basal contacts (Huttner and Brand, 1997; Farkas and Huttner, 2008), begin to express astroglia-specific markers (Campbell and Götz, 2002; Kriegstein and Alvarez-Buylla, 2009), lose their tight junctions and elongate (Kelava and Huttner, 2012). These apical radial glia (aRG) perform interkinetic nuclear migration (Taverna and Huttner, 2010), like neuroepithelial cells, and divide asymmetrically at the apical surface of the VZ (Götz and Huttner, 2005; Fietz and Huttner, 2011; Lui et al., 2011) in order to produce a neuron, intermediate progenitor (IP), or basal radial glia (bRG) (Miyata et al., 2001, 2004; Noctor et al., 2001, 2004; Haubensak et al., 2004; Fietz et al., 2010; Hansen et al., 2010; Reillo et al., 2011). IPs and bRG, like neurons, delaminate from the apical surface and translocate their nucleus to the basal region of the $\mathrm{VZ}$ to form the second germinal layer, the SVZ, where non-polar IPs self-consume to produce two neurons and unipolar bRGs generate neurons asymmetrically via IPs or transit-amplifying progenitors (TAPs) (Fietz and Huttner, 2011; Franco and Müller, 2013).

In gyrencephalic species, such as the human and ferret, an abundance of basal-oriented progenitors form not only the SVZ, but subdivide the SVZ into an outer (OSVZ) and inner (ISVZ) region (Smart et al., 2002), each with a distinct expression profile (Fietz et al., 2012). The presence of an OSVZ populated by bRG is thought to be necessary for gyrencephaly: lissencephalic species (e.g., mouse, rat, rabbit) lack this derived region, whereas gyrencephalic species (e.g., human, macaque, ferret) maintain this region. But neither the presence of bRG, which constitute a small minority of SVZ progenitors in the mouse (Shitamukai et al., 2011; Wang et al., 2011), nor an abundance of bRG, which exist in comparable proportions in the lissencephalic marmoset and gyrencephalic human (Kelava et al., 2012), is sufficient for developing a folded neocortex. Several lines of evidence and hypothetical modeling may evince which neurobiological features are both necessary and sufficient for development of a gyrencephalic neocortex.

\section{AXONAL TENSION AND LATE-STAGE PLASTICITY IN CORTICAL FOLDING}

The first cortico-cortical and cortico-subcortical tracts emerge during development of the preplate. As radial pathways across the cortical mantle gradually regress, the subplate forms and thalamo-cortical fibers advance into the cortical plate and cortico-cortical pathways emerge (Kostovic and Rakic, 1990; De Carlos and O'Leary, 1992; Kostović and Jovanov-Milosević, 2006; Kostović and Judas, 2010). In humans, both the radial organization of fiber tracts and establishment of pathways proceed along a posterodorsal $\rightarrow$ anteroventral gradient, with gyri formation beginning at the parieto-occipital and central sulci during GW24 (Takahashi et al., 2012). One of the earliest suggested and most widely debated hypotheses of a developmental cause for folding focuses on the mechanical tension of axons (Van Essen, 1997). The so-called tension-based hypothesis states that strong, tangentially organized cortico-cortical and weak, radially organized cortico-subcortical pathways, in an effort to minimize the distance between interconnected regions, cause the outward and inward folding of the cortex, respectively.

A recent extension of this hypothesis, which ascribes axonal tensions through the white matter the responsibility of pulling inward the cortical surface, proposes that cortical folding is a function of white matter connectivity (Mota and HerculanoHouzel, 2012). While the emergence of primary sulci with long associative fiber tracts is conserved in gyrencephalic species, as is the close correlation between white matter volume and gyrencephaly during development, no direct connection between gyrification and white matter myelination has been observed (Neil et al., 1998). More importantly, the crucial assumption in tension-based hypotheses - that axonal tension is directed across gyri - finds little evidence in its defense (Figure 3). Work in the ferret has shown that, while axons are under considerable tension in the developing brain, the tension is predominantly located in subcortical axon bundles, too deep to affect folding at the surface, and that there is no significant circumferential axonal tension in developing gyri (Xu et al., 2010). In humans, no relationship is observed between gyral formation and the establishment of cortico-cortical fiber pathways (Takahashi et al., 2012). Therefore, axonal tension is unlikely to causally affect cortical folding. However, radial tension within gyri, regulated by white matter connectivity, may limit expansion of the cortex and thereby mediate the shape of the cortical surface (Toro and Burnod, 2005).

Regional variations in axonal tension across the cortex have been suggested to affect cortical shape and influence local folding patterns (Hilgetag and Barbas, 2006; Toro et al., 2008), indicating 


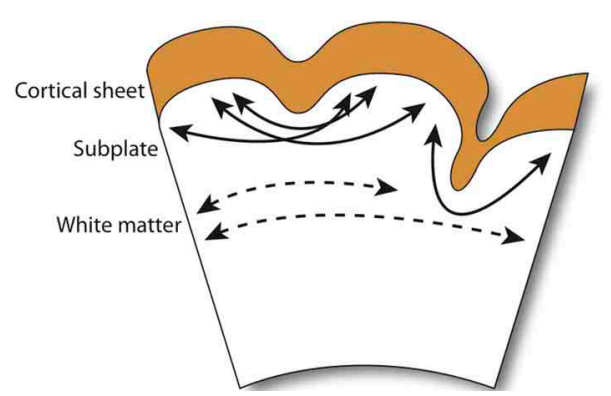

FIGURE 3 | Observed axonal tension across neocortical gyri. Axonal tension (arrows) is distributed circumferentially across the subcortical white matter (dashed arrows), but radially in the subplate and gyral folds (filled arrows). Contrary to the connectivty-driven hypothesis (see section 4), circumferential tension is not observed across neocortical gray matter ( $\mathrm{Xu}$ et al., 2010).

that axonal tension is either the driving force behind late-stage increases in species-specific gyrification or that early-stage tension forces - too small to drive cortical folding by mechanical deformation-may, nonetheless, provide feedback signals that trigger patterns of differential growth in the germinal zone (see Beloussov, 1998). The coincident emergence of primary sulci with long associative fiber tracts lends support to the latter scenario, wherein the subplate zone plays host to interactions between developing fiber tracts and the production and migration of immature neurons (Kostovic and Rakic, 1990; Armstrong et al., 1995). On the other hand, axonal tension is not observed to induce morphological deformations (Knutsen et al., 2013); so, regional variation in cortical tension, proceeding from a topology of gyri and sulci established by differential gray matter (GM) growth, is more likely to only tinker with late-stage gyrencephaly. Minor intraspecific differences in gyri and sulcal formation, particularly in the late-forming prefrontal cortex, support this scenario (Toro et al., 2008).

\section{EXPANSION OF THE OSVZ INCREASES CORTICAL SURFACE AREA}

The fibers of polarized progenitors provide scaffolding to guide migrating neurons to the developing cortex. In the OSVZ, the scaffolding of bRG resembles a fan, which modifies the trajectory of migrating neurons by driving them to expand conically (Figure 4) (Fietz and Huttner, 2011; Lui et al., 2011; Borrell and Reillo, 2012). This, in turn, increases cortical surface area; and experimentally increasing or decreasing cortical surface area during development leads to the production or reduction of gyri, respectively (Reillo et al., 2011). While the caudal $\rightarrow$ rostral gradient of cortical folding tends to mirror the transverse gradient of neurogenesis (Smart and McSherry, 1986), no gyrencephalic species has a uniform distribution of gyri and sulci, but a pattern that reflects both functional specialization and phylogenetic inheritance. Therefore, the topology of gyri should be reflected in the distribution and mitotic activity of OSVZ progenitors in the developing neocortex. And so it is. In the cat, the density of OSVZ mitoses is three-fold higher in the prospective parietal compared to temporal cortex, reflecting the higher degree of folding and

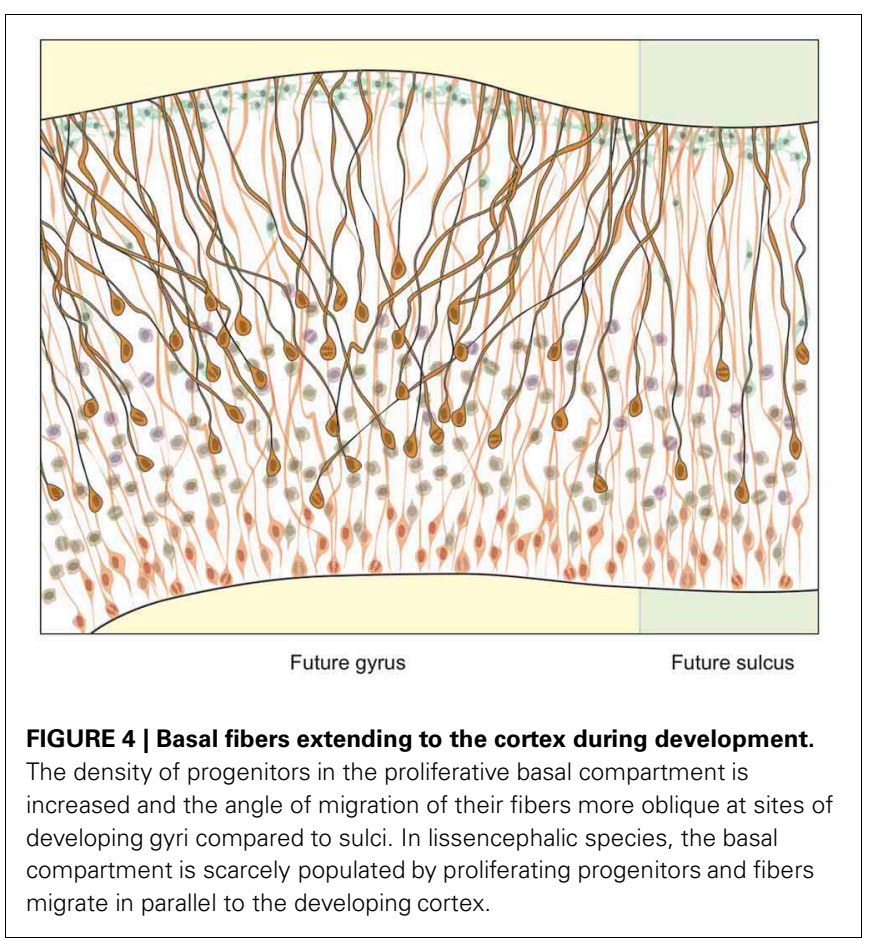

expanded surface area in the former compared to the latter region; in the ferret, the density of OSVZ mitoses is three-fold higher in the prospective splenial gyrus than lateral sulcus, reflecting the relative conical expansion and cortical folding of those regions; and in the human and monkey, OSVZ mitoses are most abundant in the highly folded parietal and temporal regions (Lukaszewicz et al., 2005; Reillo et al., 2011). The evidence suggests, therefore, that OSVZ progenitors accumulate and/or cycle faster in regions that will undergo the greatest cortical folding.

The degree of cissoidian radial fiber divergence, which drives 3D conical expansion of the cortical surface, increases exponentially during neurogenesis in prospective gyral regions, but remains mostly parallel in smooth regions, as it does in lissencephalic species (Lui et al., 2011; Borrell and Reillo, 2012). Importantly, it is not the production of neurons but the divergence of radial fibers (which may be an evolutionary response to increases in neuron production) that drives conical expansion. Enucleation studies in the ferret show how a reduction in the proliferation of bRG leads to a smaller, but no less gyrified, splenial gyrus (Reillo et al., 2011). The mechanistic, and likely genetic (see section 2), dissociation of neuron production and cortical folding is also clear in disease phenotypes. Pachygyria, for example, is characterized by a decrease in cortical surface area, but not neuron number (Ross and Walsh, 2001), whereas the decrease in neuron number in microcephaly is not accompanied by a commensurate loss in cortical folding (Bond et al., 2002). However, the dissociation of neuron production and cortical folding in development does not necessarily imply that these traits were subject to distinct selection pressures. On the contrary, the ubiquity of enlarged, gyrencephalic brains across the mammalian phylogeny, and the near absence of large-brained lissencephalic species, strongly suggests that neocortical expansion and folding evolved in concert. 


\section{GYRENCEPHALY AND CORTICAL THINNING AS MECHANISTIC RESPONSES TO EVOLUTIONARY INCREASES IN NEURON PRODUCTION}

Given two brains of equal radial dimensions, the more folded specimen tends to have a thinner cortex (Hofman, 1985; Pillay and Manger, 2007). In humans, a thin and extensively folded neocortex is characteristic of polymicrogyria (Rakic, 1988; Chang et al., 2004) and may manifest in schizophrenia (Harrison, 1999; Palaniyappan and Liddle, 2012), Williams syndrome (Gaser et al., 2006), and autism (Jou et al., 2010). Across species, the most gyrencephalic taxa (cetartiodactyla) also have the thinnest cortices (Manger et al., 2012). Nonetheless, the relationships between brain volume, gyrencephaly, and GM cortical thickness, in development and evolution, remain elusive (Figure 5).

GM thickness and GI-like brain volume, cortical surface area, and gray matter volume-are heritable traits (Panizzon et al., 2009; Eyler et al., 2012). But while brain volume, cortical surface area, and gray matter volume show high levels of statistical and genetic correlation within a population, GM thickness and GI are lowly or negatively correlated with most neuroanatomical traits (Rogers et al., 2010; Winkler et al., 2010). In mammalian evolution, we also find a somewhat chaotic correlative pattern of GM thickness (Figure 5). Cetaceans are the most gyrencephalic mammals and exhibit a thin cortex $(<1.75 \mathrm{~mm})$ and low neuron density ( $<65,000$ per $\mathrm{mm}^{3}$ ) (Hof et al., 2005; Kern et al., 2011); but despite a magnitude of variation in brain volume across cetacean species, GI values remain nearly constant. Pinnipeds, the aquatic carnivores, likewise show very high levels of gyrencephaly (Manger et al., 2012). So perhaps adaptation to an aquatic environment releases a constraint on evolving increasingly folded cortices (see Butti et al., 2011). However, the manatee, the only other aquatic mammal, has a relatively large, lissencephalic brain and a thick cortex $(\sim 3 \mathrm{~mm})$ (Reep et al., 1989; Reep and O'Shea, 1990; Marshall and Reep, 1995). Among terrestrial mammals, artiodactyls have the highest GI values, as well as distinctly thin cortices and low neuron densities compared to primates and carnivores (Chow, 1950), whereas the relatively large-brained beaver, like the manatee, is lissencephalic (Pillay and Manger, 2007). A loose negative correlation between GI and relative (i.e., corrected for neocortical volume) ventricular volume $\left[F_{(1,30)}=3.834, P=\right.$ 0.06 may explain the large ventricles and smooth cortices of the beaver and manatee. Furthermore, our analyses find significant scaling relationships between GM thickness and both brain weight and neuron density (Figure 6) (Harrison et al., 2002). These data support the observed convergence of GM thinning in large-brained species, but not the lack of correlation between GM thickness and other neuroanatomical variables within human and other primate populations (see above). If the genes, and therefore selection pressures, mediating GM thickness and folding are independent of those mediating other brain variables, as our and previous analyses suggest, then we should consider a developmental scenario wherein cortical folding and thinning become advantageous to selection for increases in neuron number.

There is a 1000 -fold difference in cortical neuron number between mouse and human, but only a 10 -fold difference in the length of the neurogenic period. The increase in neuron number in human, therefore, means an exponential amplification of neuron generation. As discussed in section 3, neurons in the human and other large-brained species are generated primarily in the OSVZ, where immature neurons migrate to the cortical plate along fibers provided by bRG. It is the divergence of these fibers that drives conical expansion and ultimately gyrification of the neocortex (see section 5). However, the divergence of radial fibers exiting the OSVZ only organize the migration of neurons to the cortex, allowing them to fan out across an expanding surface rather than continue to populate an overcrowding cortical column (i.e., radial fiber divergence has adapted to accommodate selection for increased neuron generation). The ubiquity of gyrencephaly across mammalian orders, absent any genetic correlation between brain volume and GI (see above), suggests that the mechanistic ability for radial fibers in the OSVZ to diverge in response to rapid increases in neuron generation is either extremely adaptable or deeply homologous (i.e., the conical expansion of fibers is likely constrained by mechanistic limitations or by a conserved developmental toolbox that makes any other solution to the problem of increasing neuron generation deleteriously demanding). But in either case, cortical folding is simply a conserved, mechanistic response to selection for an increased generation of neurons per neurogenic period. In the next section, we will discuss how maintenance of a proliferative niche in the OSVZ may underpin such increases in neuron generation.

\section{MAINTENANCE OF A BASAL PROLIFERATIVE NICHE DURING PEAK NEUROGENESIS}

Conical expansion of the SVZ into outer and inner regions is a hallmark of increased neurogenic proliferative capacity (Smart et al., 2002). It is likely necessary — but not sufficient (Kelava et al., 2012) - to generate a gyrencephalic neocortex. In the human OSVZ, bRG cells may generate neurons via TAPs, progenitor cells capable of multiple rounds of proliferation (Hansen et al., 2010); and while TAPs are putatively present in other large-brained, highly gyrencephalic species, they have not been observed in significant numbers or with comparable proliferative capacity in lissencephalic species (Wang et al., 2011). Intrinsic factors, such as the expression level and inheritance of certain transcription factors (e.g., Pax6, Sox2) likely play a role in the proliferative capacity of bRG and TAPs, but there is accumulating evidence that extrinsic factors distinguish the behavior of progenitors in the basal compartment between lissencephalic and gyrencephalic species.

Extracellular matrix has been implicated in expansion of the SVZ (Barros et al., 2011; Fietz et al., 2012). For example, interference with integrin signaling, a major part of ECM-derived signaling, results in a reduced number of bRG without affecting the TAP/IP population (Fietz et al., 2010). This suggests that the proliferative capacity of bRGs, compared to TAPs/IPs, depends on integrin signaling maintained via the basal process. Furthermore, there is a denser invasion of incoming thalamic fibers in the SVZ of gyrencephalic compared to lissencephalic species. These fibers secrete proliferation-promoting factors (Kriegstein and AlvarezBuylla, 2009; Dehay et al., 2001) and subdivide the SVZ into an outer and inner region in gyrencephalic species (Smart et al., 2002). Work in the mouse has shown that blood vessels in the SVZ, which have basal lamina, establish a proliferative niche 


\section{A}

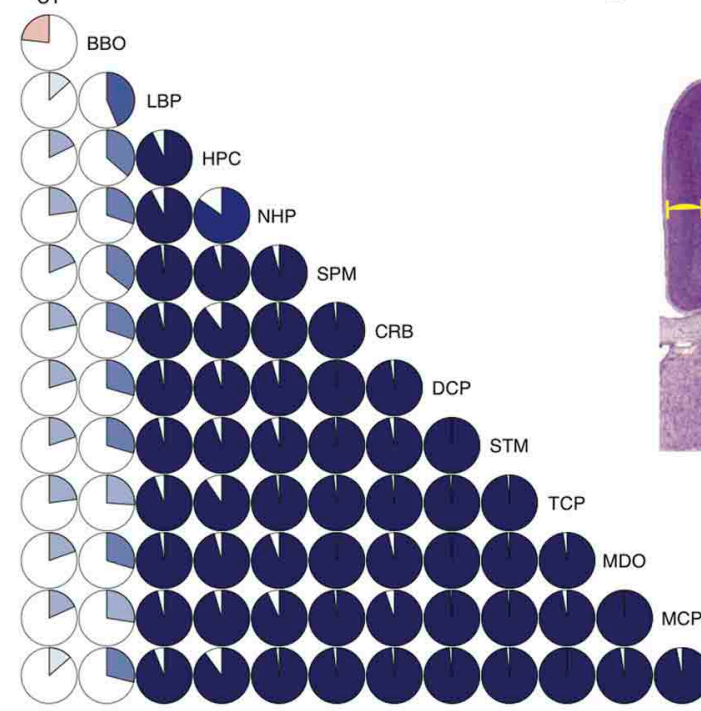

C

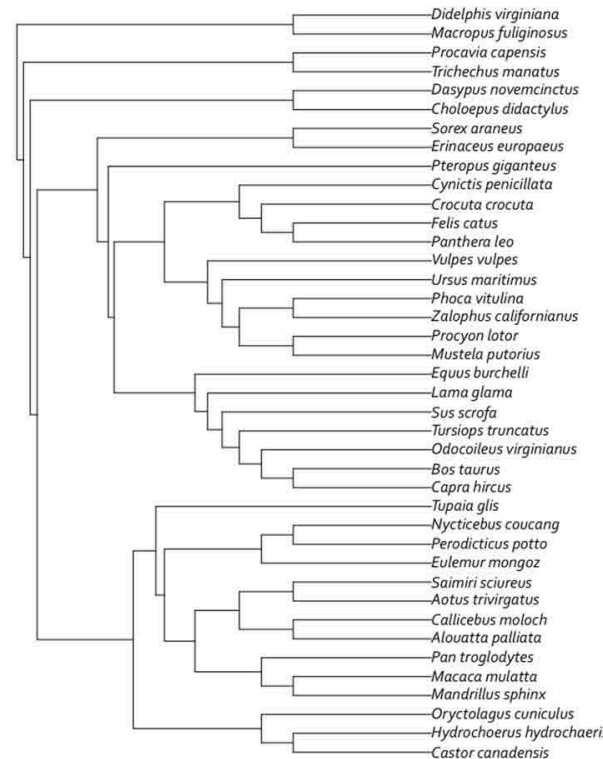

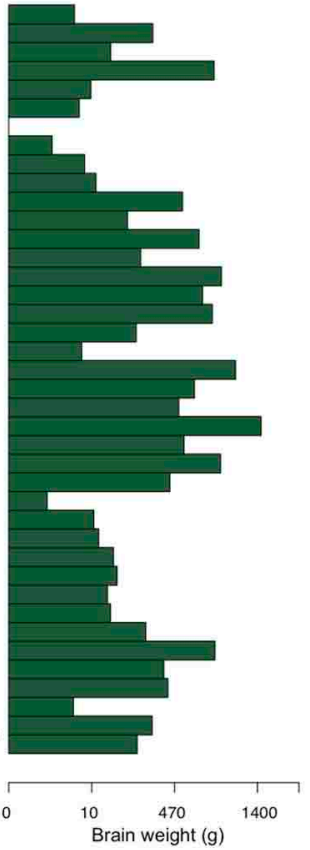

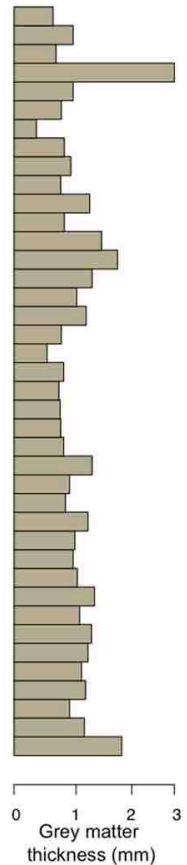

FIGURE 5 | Gray matter cortical thickness varies with brain regions and phylogeny. (A) Twelve brain region volumes and GM thickness presented in a pie-chart matrix of positive (blue gradient) and negative (red gradient) correlations. Note that all brain region volumes - except BBO, which is a developmentally and functionally separate region - show very high $\left(R^{2}>0.8\right)$ positive correlations, whereas cortical thickness is lowly $\left(R^{2}<0.4\right)$ correlated with all brain region volumes. $\mathrm{BBO}$, olfactory bulb; $\mathrm{CRB}$, cerebellum; $\mathrm{CT}$, cortical thickness; DCP, diencephalon; HPC, hippocampus; LBP, piriform lobe; MCP, mesencephalon; MDO, medulla oblongata; NHP, neurohypophysis;
NPL, neopallial; SPM, septum; STM, striatum; TCP, telencephalon. Volumetric data from Stephan et al. (1981). (B) GM thickness is measured as the average distance between layers I and VI (yellow bars) in a systematic random sample of the neocortex. (C) A phylogenetic tree of 40 mammal species (Bininda-Emonds et al. 2007) showing the distribution of brain weight $(\log 10+1)$ and GM thickness $(\log 10+1)$ across species. GM thickness in all species was measured with Fiji (Schindelin et al., 2012) on slides from brainmuseum.org. See Lewitus et al. (2013) and Table A1 for neuroanatomical data in (C). in their vicinity (Javaherian and Kriegstein, 2009; Stubbs et al., 2009), so vascularization of the developing neocortex is also likely to be integral to the establishment and maintenance of a proliferative SVZ. While it remains unknown which factors are secreted by blood vessels, basal processes, and other ECM vehicles to determine the proliferative capacity of the basal compartment, transcriptome analyses of the developing neocortex in human and mouse have revealed an enrichment of ECM-related transcripts, not only in the OSVZ compared to the VZ, but also in the human OSVZ compared to the mouse SVZ (Arai et al., 2011; Fietz 

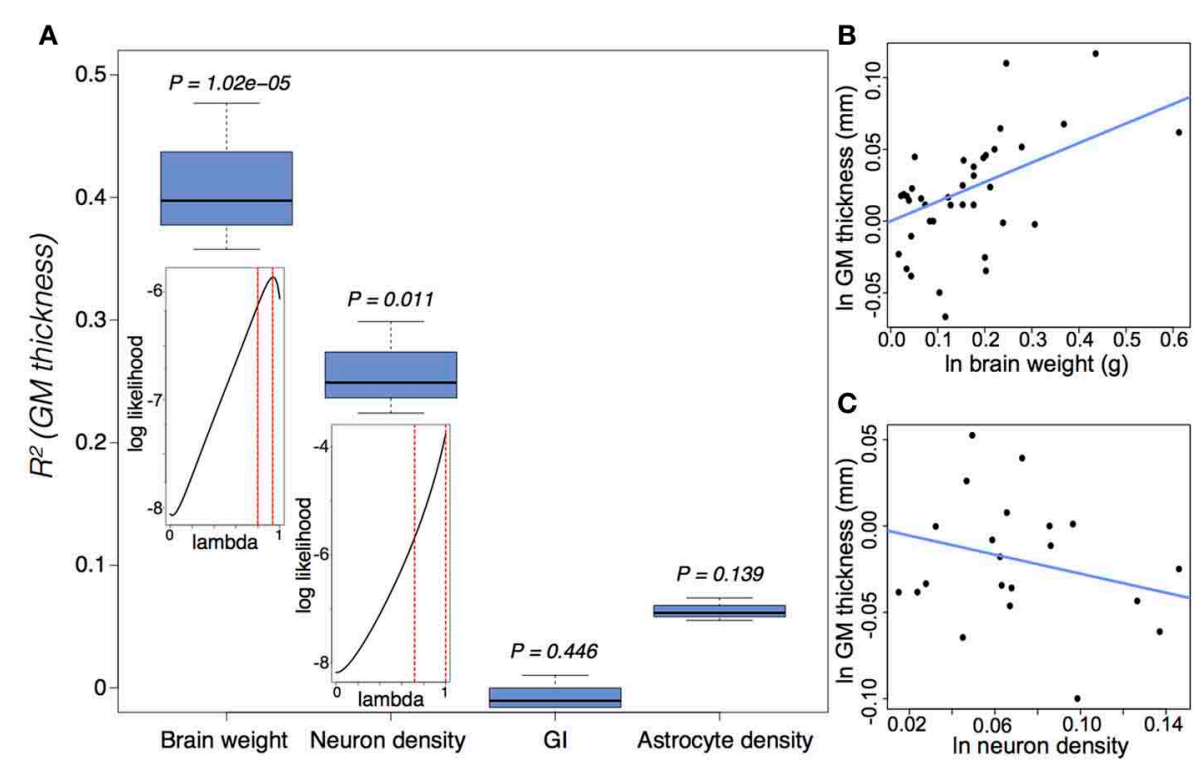

FIGURE 6 | Gray matter (GM) thickness is a function of brain weight and neuron density. (A) Variation in GM thickness can be significantly explained by brain weight $\left[F_{(2,37)}=22.58, P=3.9 \times 10^{-7}\right]$ and neuron density $\left[F_{(2,20)}=7.96, P=0.003\right]$, but not by either GI $\left[F_{(2,38)}=0.066, P=0.936\right]$ or astrocyte density $\left[F_{(2,20)}=2.37, P=0.119\right]$. The insets suggest a strong phylogenetic signal (Pagel, 1999), tantamount to a random walk, in the scaling of GM thickness as a function of brain weight (lambda $\left.=0.89_{(-0.09)}^{(+0.07)}\right)$ and neuron density (lambda $\left.=0.88_{(-0.17)}^{(+0.12)}\right)$. (B,C) Ln-transformed phylogenetically independent contrasts with regression through the origin for GM thickness as a function of (B) brain weight and (C) neuron density. GM thickness scales positively as a function of brain weight $\left(e^{0.136 \pm 0.027}\right)$ and negatively as a function of neuron density $\left(e^{-0.276 \pm 0.098}\right)$. Cell densities pertain to gray matter counts in the visual cortex from Lewitus et al. (2012). See (Lewitus et al., 2013) and Table A1 for neuroanatomical data. et al., 2012), providing clear evidence for an interplay between ECM signaling, an expanded basal compartment, and a large, gyrencephalic neocortex.

\section{CONCLUSION}

Brain size is subject to significant heritability. As such, selection pressures directing brain evolution in humans have ranged from tool-making abilities to diet to long-distance running [reviewed in Healy and Rowe (2007)]. While none of these pressures is likely to be solely responsible for human neocortical expansion-nor can any of them be incorporated into a general theory of mammalian neocortical expansion-the fact remains: the neocortex has expanded many times in mammalian evolution; and the features underwriting that expansion may ultimately be traced back to neurogenic changes at the cellular level. What remains to be understood, however, is which features are highly constrained and which features have been repeatedly implicated in neocortical evolution.

Adult mammalian brains are not identical at the cellular level. Phylogenetic differences in the density of cortical columns and in the morphology and biochemistry of neurons have been identified in most orders (e.g., Beaulieu, 1993; Peters and Yilmaz, 1993; Nimchinsky et al., 1999; Preuss and Coleman, 2002; Hof and Van der Gucht, 2007; Herculano-Houzel, 2011). The configuration of structural and functional topographical maps that constitute the mammalian brain, too, has seen many evolutionary examples of proliferation, addition, and segregation [reviewed in Krubitzer and Seelke (2012)]. Therefore, universal modular architecture does not exist for the mammalian neocortex and neocortical size may not fairly be considered as an index of general functional capacity. Differential growth across the neocortex and between species, however, may tell us how variation in neocortical size is achieved, even if it will not necessarily inform us of the environmental selection pressures effecting that variation. Here, we have taken a reductionist approach by claiming that a gross neuroanatomical feature (neocortical folding) may signify differences in neurogenic programming both within an individual and across species. We have made this claim based on evidence that neocortical size is determined before any neuronal connections are established and on the assumption that the formation of neocortical gyri is the result of an interaction between selection pressures in cognitive or sensory behavior and the cellbiological properties of neural progenitors throughout neurogenesis. Neocortical size is determined by neurogenic programming (i.e., the distribution of progenitor-type populations and the differential regulation of those populations during neurogenesis). Some neocortical regions may have higher neuron numbers or densities requiring greater degrees of local modulation and control (Collins et al., 2010; Collins, 2011; Bianchi et al., 2012). In these regions, tremendous perinatal increases in astrocytes and oligodendrocytes will drive the morphological expansion of neocortical regions. Specializations in behavior are known to be complemented by cellular or molecular enhancements in the regions of the brain mediating those specializations (Krubitzer, 2007). The enlargement of Meynert cells in the visual cortex of monkeys compared to carnivores, for example, is thought to represent 
the evolution of a cellular substrate for specialized sensorimotor capacities related to eye-hand movements that are highly developed in monkeys compared to carnivores (le Gros Clark, 1942; Sherwood et al., 2003). Similarly, the introduction of acoustic noise to rat pups has been shown to alter the cortical magnification of particular neuronal frequencies in the primary auditory cortex (Chang and Merzenich, 2003), showing that even within an individual behavioral and cellular adaptations are tightly linked. In the case of mammalian neocortical expansion, we observe increased vascularization of the neocortical germinal zone, subdivision of the SVZ into an outer and inner region, expansion of the OSVZ, upregulation of ECM signaling to abventricular progenitors, and increased proliferative capacities of non-polar progenitors in the basal compartment of large-brained, gyrencephalic species. We think that these features are correlated in both development and evolution and that any variation between

\section{REFERENCES}

Arai, Y., Pulvers, J. N., Haffner, C., Schilling, B., Nüsslein, I., Calegari, F., et al. (2011). Neural stem and progenitor cells shorten s-phase on commitment to neuron production. Nat. Comm. 2:154. doi: 10.1038/ncomms1155

Armstrong, E., Schleicher, A., Omran, H., Curtis, M., and Zilles, K. (1995). The ontogeny of human gyrification. Cereb. Cortex, 5, 56-63. doi: 10.1093/cercor/5.1.56

Barnette, A. R., Neil, J. J., Kroenke, C. D., Griffith, J. L., Epstein, A. A., Bayly, P. V., et al. (2009). Characterization of brain development in the ferret via MRI. Pediatr. Res. 66, 80-84. doi: 10.1203/PDR.0b013e3181a291d9

Barros, C. S., Franco, S. J., and Müller, U. (2011). Extracellular matrix: functions in the nervous system. Cold Spring Harb. Perspect. Biol. 3:a005108. doi: 10.1101/cshperspect.a005108

Bayer, S. A., and Altman, J. (1991). Neocortical Development. New York, NY: Raven Press.

Beaulieu, C. (1993). Numerical data on neocortical neurons in adult rat, with special reference to the GABA population. Brain Res. 609, 284-292. doi: 10.1016/00068993(93)90884-P

Beloussov, L. V. (1998). The Dynamic Architecture of a Developing Organism: an Interdisciplinary Approach to the Development of Organisms. Dordrecht: Kluwer, 145-163.

Bianchi, S., Stimpson, C. D., Bauernfeind, A. L., Schapiro, S. J., Baze, W. B., McArthur, M. J., et al. (2012). Dendritic morphology of pyramidal neurons in the chimpanzee neocortex: regional specializations and comparison to humans. Cereb. Cortex. doi: 10.1093/cercor/bhs239. [Epub ahead of print].

Bond, J., Roberts, E., Mochida, G. H., Hampshire, D. J., Scott, S., Askham, J. M., et al. (2002). ASPM is a major determinant of cerebral cortical size. Nat. Genet. 32, 316-320. doi: $10.1038 / \mathrm{ng} 995$

Borrell, V., and Reillo, I. (2012). Emerging roles of neural stem cells in cerebral cortex development and evolution. Dev. Neurobiol. 72, 955-971. doi: 10.1002/dneu. 22013

Butti, C., Raghanti, M. A., Sherwood, C. C., and Hof, P. R. (2011). The neocortex of cetaceans: cytoarchitecture and comparison with other aquatic and terrestrial species. Ann. N.Y. Acad. Sci. 1225, 47-58. doi: 10.1111/j.1749-6632. 2011.05980.x

Campbell, K., and Götz, M. (2002). Radial glia: multi-purpose cells for vertebrate brain development. Trends Neurosci. 25, 235-238. doi: $10.1016 / \mathrm{S} 0166-2236$ (02)02156-2

Chang, B. S., Piao, X., Giannini, C., Cascino, G. D., Scheffer, I., Woods, C. G., et al. (2004). Bilateral generalized polymicrogyria (BGP): a distinct syndrome of cortical malformation. Neurology 62, 1722-1728. doi: 10.1212/ 01.WNL.0000125187.52952.E9

Chang, E. F., and Merzenich, M. M. (2003). Environmental noise retards auditory cortical development. Science 300, 498-502. doi: 10.1126/science.1082163

Chi, J. G., Dooling, E. C., and Gilles, F. H. (1977). Gyral development of the human brain. Ann. Neurol. 1, 86-93. doi: 10.1002/ana.410010109

individuals or species in neocortical morphology will not only be underwritten by changes in neurogenic programming but will also be constrained by limitations imposed by the mammalian neurogenic program.

\section{ACKNOWLEDGMENTS}

We would like to thank the reviewers for their assistance in improving our manuscript. Eric Lewitus would like to thank Evan Charles for helpful discussion. Iva Kelava was a member of the International Max Planck Research School for Molecular Cell Biology and Bioengineering and a doctoral student at the Technische Universität Dresden. Wieland B. Huttner was supported by grants from the Deutsche Forschungsgemeinschaft (DFG) (SFB 655, A2; TRR 83, Tp6) and the European Research Council (250197), by the DFG-funded Center for Regenerative Therapies Dresden, and by the Fonds der Chemischen Industrie.

Chow, K. (1950). Cell ratios in the thalamocortical visual system of macaca mulatta. $J$. Comp. Neurol. 92, 227-239. doi: $10.1002 /$ cne. 900920208

Clowry, G., Molnár, Z., and Rakic, P. (2010). Renewed focus on the developing human neocortex. J. Anat. 217, 276-288.

Collins, C. E. (2011). Variability in neuron densities across the cortical sheet in primates. Brain Behav. Evol. 78, 37-50. doi: 10.1159/000327319

Collins, C. E., Airey, D. C., Young, N. A., Leitch, D. B., and Kaas, J. H. (2010). Neuron densities vary across and within cortical areas in primates. Proc. Natl. Acad. Sci. U.S.A. 107, 15927-15932. doi: 10.1073/pnas. 1010356107

De Carlos, J. A., and O'Leary, D. D. (1992). Growth and targeting of subplate axons and establishment of major cortical pathways. J. Neurosci. 12, 1194-1211.

Dehay, C., Giroud, P., Berland, M., Smart, I., and Kennedy, H. (1993). Modulation of the cell cycle contributes to the parcellation of the primate visual cortex. Nature 366, 464-466. doi: 10.1038/ $366464 \mathrm{a} 0$

Dehay, C., Savatier, P., Cortay, V., and Kennedy, H. (2001). Cell-cycle kinetics of neocortical precursors are influenced by embryonic thalamic axons. J. Neurosci. 21, 201-214.

Dubois, J., Benders, M., Cachia, A., Lazeyras, F., Ha-Vinh Leuchter, R., Sizonenko, S. V., et al. (2008). Mapping the early cortical folding process in the preterm newborn brain. Cereb. Cortex 18, 1444-1454. doi: 10.1093/cercor/bhm 180

Eyler, L. T., Chen, C.-H., Panizzon, M. S., Fennema-Notestine, C., Neale, M. C., Jak, A., et al. (2012). A comparison of heritability maps of cortical surface area and thickness and the influence of adjustment for whole brain measures: a magnetic resonance imaging twin study. Twin. Res. Hum. Genet. 15, 304-314. doi: 10.1017/thg.2012.3

Farkas, L. M., and Huttner, W. B. (2008). The cell biology of neural stem and progenitor cells and its significance for their proliferation versus differentiation during mammalian brain development. Curr. Opin. Cell Biol. 20, 707-715. doi: 10.1016/j.ceb.2008. 09.008

Fietz, S. A., and Huttner, W. B. (2011). Cortical progenitor expansion, self-renewal and neurogenesisa polarized perspective. Curr. Opin. Neurobiol. 21, 23-35. doi: 10.1016/j.conb.2010.10.002

Fietz, S. A., Kelava, I., Vogt, J., WilschBräuninger, M., Stenzel, D., Fish, J. L., et al. (2010). OSVZ progenitors of human and ferret neocortex are epithelial-like and expand by integrin signaling. Nat. Neurosci. 13, 690-699. doi: 10.1038/nn.2553

Fietz, S. A., Lachmann, R., Brandl, H., Kircher, M., Samusik, N., Schröder, R., et al. (2012). Transcriptomes of germinal zones of human and mouse fetal neocortex suggest a role of extracellular matrix in progenitor self-renewal. Proc. Natl. Acad. Sci. U.S.A. 109, 11836-11841. doi: 10.1073/pnas. 1209647109

Franco, S. J., and Müller, U. (2013). Shaping our minds: stem and progenitor cell diversity in the mammalian neocortex. Neuron 77, 19-34. doi: 10.1016/j.neuron.2012.12.022

Fukunishi, K., Sawada, K., Kashima, M., Sakata-Haga, H., Fukuzaki, K., and Fukui, Y. (2006). Development 
of cerebral sulci and gyri in fetuses of cynomolgus monkeys (macaca fascicularis). Anat. Embryol. 211, 757-764. doi: 10.1007/s00429-0060136-7

Gaser, C., Luders, E., Thompson, P. M., Lee, A. D., Dutton, R. A., Geaga, J. A., et al. (2006). Increased local gyrification mapped in williams syndrome. Neuroimage 33, 46-54. doi: 10.1016/j.neuroimage.2006.06.018

Götz, M., and Huttner, W. B. (2005) The cell biology of neurogenesis. Nat. Rev. Mol. Cell Biol. 6, 777-788. doi: 10.1038/nrm1739

Hansen, D. V., Lui, J. H., Parker, P. R. L., and Kriegstein, A. R. (2010). Neurogenic radial glia in the outer subventricular zone of human neocortex. Nature 464, 554-561. doi: 10.1038/nature08845

Harrison, K. H., Hof, P. R., and Wang, S. S. (2002). Scaling laws in the mammalian neocortex: does form provide clues to function? J. Neurocytol. 31, 289-298. doi: 10.1023/A:1024178127195

Harrison, P. J. (1999). The neuropathology of schizophrenia. a critical review of the data and their interpretation. Brain 122(Pt 4), 593-624. doi: 10.1093/brain/122.4.593

Haubensak, W., Attardo, A., Denk, W., and Huttner, W. B. (2004). Neurons arise in the basal neuroepithelium of the early mammalian telencephalon: a major site of neurogenesis. Proc. Natl. Acad. Sci. U.S.A. 101, 3196-3201. doi: $10.1073 /$ pnas. 0308600100

Healy, S. D., and Rowe, C. (2007). A critique of comparative studies of brain size. Proc. Biol. Sci. 274, 453464. doi: $10.1098 /$ rspb.2006.3748

Herculano-Houzel, S. (2011). Not all brains are made the same: new views on brain scaling in evolution. Brain Behav. Evol. 78, 22-36. doi: 10.1159/ 000327318

Hilgetag, C. C., and Barbas, H. (2006). Role of mechanical factors in the morphology of the primate cerebral cortex. PLoS Comput. Biol. 2:e22. doi: 10.1371/journal.pcbi.0020022

Hof, P. R., Chanis, R., and Marino, L. (2005). Cortical complexity in cetacean brains. Anat. Rec. 287A, 1142-1152. doi: 10.1002/ar.a.20258

Hof, P. R., and Van der Gucht, E. (2007). Structure of the cerebral cortex of the humpback whale, megaptera novaeangliae (cetacea, mysticeti, balaenopteridae). Anat. Rec. (Hoboken) 290, 1-31. doi: 10.1002/ar.20407

Hofman, M. A. (1985). Size and shape of the cerebral cortex in mammals. i. the cortical surface. Brain Behav. Evol. 27, 28-40. doi: $10.1159 / 000118718$

Huttner, H. B., Lohmann, G., and von Cramon, D. Y. (2005). Magnetic resonance imaging of the human frontal cortex reveals differential anterior-posterior variability of sulcal basins. Neuroimage 25, 646-651. doi: 10.1016/j.neuroimage.2004.12.008

Huttner, W. B., and Brand, M. (1997). Asymmetric division and polarity of neuroepithelial cells. Curr. Opin. Neurobiol. 7, 29-39. doi: 10.1016/S0959-4388(97)80117-1

Javaherian, A., and Kriegstein, A. (2009). A stem cell niche for intermediate progenitor cells of the embryonic cortex. Cereb. Cortex 19(Suppl. 1), i70-i77. doi: 10.1093/cercor/bhp029

Jou, R. J., Minshew, N. J., Keshavan, M. S., and Hardan, A. Y. (2010). Cortical gyrification in autistic and asperger disorders: a preliminary magnetic resonance imaging study. J. Child Neurol. 25, 1462-1467. doi: 10.1177/0883073810368311

Kashima, M., Sawada, K., Fukunishi, K., Sakata-Haga, H., Tokado, H., and Fukui, Y. (2008). Development of cerebral sulci and gyri in fetuses of cynomolgus monkeys (macaca fascicularis). II. gross observation of the medial surface. Brain Struct. Funct. 212, 513-520. doi: 10.1007/s00429-008-0171-7

Kelava, I., and Huttner, W. B. (2012). "Neurogenesis in the developing mammalian neocortex," in eLS. John Wiley \& Sons, Ltd. doi: 10.1002/9780470015902.a0022541

Kelava, I., Reillo, I., Murayama, A. Y., Kalinka, A. T., Stenzel, D., Tomancak, P., et al. (2012). Abundant occurrence of basal radial glia in the subventricular zone of embryonic neocortex of a lissencephalic primate, the common marmoset callithrix jacchus. Cereb. Cortex 22, 469-481. doi: 10.1093/cercor/bhr301

Kern, A., Siebert, U., Cozzi, B., Hof, P. R., and Oelschläger, $H$. H. A. (2011). Stereology of the neocortex in odontocetes: qualitative, quantitative, and functional implications. Brain Behav. Evol. 77, 79-90. doi: 10.1159/ 000323674

Knutsen, A. K., Kroenke, C. D., Chang, Y. V., Taber, L. A., and Bayly, P. V. (2013). Spatial and temporal variations of cortical growth during gyrogenesis in the developing ferret brain. Cereb. Cortex 23, 488-498. doi: 10.1093/cercor/ bhs 042
Kochunov, P., Castro, C., Davis, D., Dudley, D., Brewer, J., Zhang, Y., et al. (2010). Mapping primary gyrogenesis during fetal development in primate brains: high-resolution in utero structural MRI study of fetal brain development in pregnant baboons. Front Neurosci. 4:20. doi: 10.3389/fnins. 2010.00020

Kostović, I., and Jovanov-Milosević, $\mathrm{N}$. (2006). The development of cerebral connections during the first 20 45 weeks' gestation. Semin. Fetal Neonatal. Med. 11, 415-422.

Kostović, I., and Judas, M. (2010). The development of the subplate and thalamocortical connections in the human foetal brain. Acta Paediatr. 99, 1119-1127.

Kostovic, I., and Rakic, P. (1990). Developmental history of the transient subplate zone in the visual and somatosensory cortex of the macaque monkey and human brain. J. Comp. Neurol. 297, 441-470. doi: 10.1002/cne.902970309

Kriegstein, A., and Alvarez-Buylla, A. (2009). The glial nature of embryonic and adult neural stem cells. Annu. Rev Neurosci. 32, 149-184. doi: 10.1146/ annurev.neuro.051508.135600

Krubitzer, L. (2007). The magnificent compromise: cortical field evolution in mammals. Neuron 56, 201-208. doi: 10.1016/j.neuron.2007.10.002

Krubitzer, L. A., and Seelke, A. M. H. (2012). Cortical evolution in mammals: the bane and beauty of phenotypic variability. Proc. Natl. Acad. Sci. U.S.A. 109(Suppl. 1), 10647-10654. doi: 10.1073/pnas.1201891109

le Gros Clark, W. E. (1942). The cells of meynert in the visual cortex of the monkey. J. Anat. 76( $\mathrm{Pt} 4$ ), 369376.1 .

Lewitus, E., Hof, P. R., and Sherwood, C. C. (2012). Phylogenetic comparison of neuron and glia densities in the primary visual cortex and hippocampus of carnivores and primates. Evolution 66, 2551-2563. doi 10.1111/j.1558-5646.2012.01601.x

Lewitus, E., Kelava, I., Kalinka, A. T., Tomancak, P., and Huttner, W. B. (2013). An adaptive threshold in mammalian neocortical evolution. arXiv 1304.5412.

Lui, J. H., Hansen, D. V., and Kriegstein, A. R. (2011). Development and evolution of the human neocortex. Cell $146,18-36$.

Lukaszewicz, A., Savatier, P., Cortay, V., Giroud, P., Huissoud, C., Berland, M., et al. (2005). G1 phase regulation, area-specific cell cycle control, and cytoarchitectonics in the primate cortex. Neuron 47, 353-364. doi: 10.1016/j.neuron.2005.06.032

Manger, P. R., Prowse, M., Haagensen, M., and Hemingway, J. (2012). Quantitative analysis of neocortical gyrencephaly in african elephants (Loxodonta africana) and six species of cetaceans: comparison with other mammals. J. Comp. Neurol. 520, 2430-2439. doi: $10.1002 /$ cne. 23046

Marshall, C. D., and Reep, R. L. (1995). Manatee cerebral cortex: cytoarchitecture of the caudal region in trichechus manatus latirostris. Brain Behav. Evol. 45, 1-18. doi: 10.1159/000113381

Mayhew, T. M., Mwamengele, G. L., Dantzer, V., and Williams, S. (1996). The gyrification of mammalian cerebral cortex: quantitative evidence of anisomorphic surface expansion during phylogenetic and ontogenetic development. J. Anat. 188(Pt 1), 53-58.

Miyata, T., Kawaguchi, A., Okano, H., and Ogawa, M. (2001). Asymmetric inheritance of radial glial fibers by cortical neurons. Neuron 31, 727-741. doi: 10.1016/S08966273(01)00420-2

Miyata, T., Kawaguchi, A., Saito, K., Kawano, M., Muto, T., and Ogawa, M. (2004). Asymmetric production of surface-dividing and nonsurface-dividing cortical progenitor cells. Development 131, 3133-3145. doi: $10.1242 /$ dev.01173

Mota, B., and Herculano-Houzel, S. (2012). How the cortex gets its folds: an inside-out, connectivity-driven model for the scaling of mammalian cortical folding. Front. Neuroanat. 6:3.doi: 10.3389/fnana.2012.00003

Neil, J. J., Shiran, S. I., McKinstry, R. C., Schefft, G. L., Snyder, A. Z., Almli, C. R., et al. (1998). Normal brain in human newborns: apparent diffusion coefficient and diffusion anisotropy measured by using diffusion tensor MR imaging. Radiology 209, 57-66.

Nimchinsky, E. A., Gilissen, E., Allman, J. M., Perl, D. P., Erwin, J. M. and Hof, P. R. (1999). A neuronal morphologic type unique to humans and great apes. Proc. Natl. Acad. Sci. U.S.A. 96, 5268-5273. doi: 10.1073/pnas.96.9.5268

Noctor, S. C., Flint, A. C., Weissman, T. A., Dammerman, R. S., and Kriegstein, A. R. (2001). Neurons derived from radial glial cells establish radial units in neocortex. Nature 409, 714-720. doi 10.1038/35055553

Noctor, S. C., Martínez-Cerdeño, V., Ivic, L., and Kriegstein, A. R. (2004). Cortical neurons arise in symmetric and asymmetric division zones and 
migrate through specific phases. Nat. Neurosci. 7, 136-144.

Pagel, M. (1999). Inferring the historical patterns of biological evolution. Nature 401, 877-884. doi: $10.1038 / 44766$

Palaniyappan, L., and Liddle, P. F. (2012). Aberrant cortical gyrification in schizophrenia: a surfacebased morphometry study. J. Psychiatry Neurosci. 37, 399-406. doi: $10.1503 /$ jpn.110119

Panizzon, M. S., Fennema-Notestine, C., Eyler, L. T., Jernigan, T. L., Prom-Wormley, E., Neale, M., et al. (2009). Distinct genetic influences on cortical surface area and cortical thickness. Cereb. Cortex 19, 2728-2735. doi: 10.1093/cercor/ bhp026

Peters, A., and Yilmaz, E. (1993). Neuronal organization in area 17 of cat visual cortex. Cereb. Cortex 3, 49-68. doi: 10.1093/cercor/3.1.49

Pillay, P., and Manger, P. R. (2007). Order-specific quantitative patterns of cortical gyrification. Eur. J. Neurosci. 25, 2705-2712. doi: 10.1111/j.1460-9568.2007.05524.x

Polleux, F., Dehay, C., and Kennedy, H. (1997a). The timetable of laminar neurogenesis contributes to the specification of cortical areas in mouse isocortex. J. Comp. Neurol. 385, 95-116.

Polleux, F., Dehay, C., Moraillon, B., and Kennedy, H. (1997b). Regulation of neuroblast cell-cycle kinetics plays a crucial role in the generation of unique features of neocortical areas. J. Neurosci. 17, $7763-7783$.

Preuss, T. M., and Coleman, G. Q. (2002). Human-specific organization of primary visual cortex: alternating compartments of dense cat-301 and calbindin immunoreactivity in layer 4A. Cereb. Cortex 12, 671-691. doi: 10.1093/cercor/12.7.671

Rakic, P. (1988). Specification of cerebral cortical areas. Science 241, 170176. doi: $10.1126 /$ science. 3291116

Reep, R. L., Johnson, J. I., Switzer, R. C., and Welker, W. I. (1989). Manatee cerebral cortex: cytoarchitecture of the frontal region in trichechus manatus latirostris. Brain Behav. Evol. 34, 365-386. doi: 10.1159/ 000116523

Reep, R. L., and O'Shea, T. J. (1990). Regional brain morphometry and lissencephaly in the sirenia. Brain Behav. Evol. 35, 185-194.

Régis, J., Mangin, J.-F., Ochiai, T., Frouin, V., Riviére, D., Cachia, A., et al. (2005). "Sulcal root" generic model: a hypothesis to overcome the variability of the human cortex folding patterns. Neurol. Med. Chir. (Tokyo) 45, 1-17.

Reillo, I., de Juan Romero, C., GarcíaCabezas, M. Á., and Borrell, V. (2011). A role for intermediate radial glia in the tangential expansion of the mammalian cerebral cortex. Cereb. Cortex 21, 1674-1694.

Rilling, J. K., and Insel, T. R. (1999). The primate neocortex in comparative perspective using magnetic resonance imaging. $J$. Hum. Evol. 37, 191-223. doi: 10.1006/jhev.1999.0313

Rogers, J., Kochunov, P., Zilles, K., Shelledy, W., Lancaster, J., Thompson, P., et al. (2010). On the genetic architecture of cortical folding and brain volume in primates. Neuroimage 53, 1103-1108. doi: 10.1016/j.neuroimage.2010.02.020

Ross, M. E., and Walsh, C. A (2001). Human brain malformations and their lessons for neuronal migration. Annu. Rev. Neurosci. 24, 1041-1070. doi: 10.1146/annurev.neuro.24.1.1041

Sawada, K., Fukunishi, K., Kashima, M., Imai, N., Saito, S., Sakata-Haga, H., et al. (2012a). Neuroanatomic and magnetic resonance imaging references for normal development of cerebral sulci of laboratory primate, cynomolgus monkeys (Macaca fascicularis). Congnit. Anom. (Kyoto) 52, 16-27. doi: 10.1111/j.1741-4520.2011.00352.x

Sawada, K., Fukunishi, K., Kashima, M., Saito, S., Sakata-Haga, H., Aoki, I., et al. (2012b). Fetal gyrification in cynomolgus monkeys: a concept of developmental stages of gyrification. Anat. Rec. (Hoboken) 295, 1065-1074. doi: 10.1002/ ar.22478

Sawada, K., Sun, X.-Z., Fukunishi, K., Kashima, M., Saito, S., Sakata-Haga, H., et al. (2010). Ontogenetic pattern of gyrification in fetuses of cynomolgus monkeys. Neuroscience 167, 735-740. doi: 10.1016/j.neuroscience.2010.02.045

Schindelin, J., Arganda-Carreras, I., Frise, E., Kaynig, V., Longair, M., Pietzsch, T., et al. (2012). Fiji: an open-source platform for biological-image analysis. Nat. Methods 9, 676-682. doi: 10.1038/nmeth.2019

Sherwood, C. C., Holloway, R. L., Gannon, P. J., Semendeferi, K., Erwin, J. M., Zilles, K., et al. (2003). Neuroanatomical basis of facial expression in monkeys, apes, and humans. Ann. N.Y. Acad. Sci. 1000, 99-103. doi: 10.1196/annals. 1280.021
Sherwood, C. C., Stimpson, C. D., Raghanti, M. A., Wildman, D. E. Uddin, M., Grossman, L. I., et al (2006). Evolution of increased glia-neuron ratios in the human frontal cortex. Proc. Natl. Acad. Sci. U.S.A. 103, 13606-13611. doi 10.1073/pnas.0605843103

Shitamukai, A., Konno, D., and Matsuzaki, F. (2011). Oblique radial glial divisions in the developing mouse neocortex induce self-renewing progenitors outside the germinal zone that resemble primate outer subventricular zone progenitors. $J$ Neurosci. 31, 3683-3695. doi 10.1523/JNEUROSCI.4773-10.2011

Smart, I. H., and McSherry, G. M. (1986). Gyrus formation in the cerebral cortex in the ferret. i. description of the external changes. J. Anat. $146,141-152$.

Smart, I. H. M., Dehay, C., Giroud, P., Berland, M., and Kennedy, $\mathrm{H}$ (2002). Unique morphological features of the proliferative zones and postmitotic compartments of the neural epithelium giving rise to striate and extrastriate cortex in the monkey. Cereb. Cortex 12, 37-53. doi: 10.1093/cercor/ 12.1.37

Stephan, H., Frahm, H., and Baron, G. (1981). New and revised data on volumes of brain structures in insectivores and primates. Folia Primatol. 35, 1-29. doi: 10.1159/ 000155963

Stubbs, D., DeProto, J., Nie, K., Englund, C., Mahmud, I., Hevner, R., et al. (2009). Neurovascular congruence during cerebral cortical development. Cereb. Cortex 19(Suppl. 1), i32-i41.

Takahashi, E., Folkerth, R. D. Galaburda, A. M., and Grant, P. E. (2012). Emerging cerebral connectivity in the human fetal brain: an MR tractography study. Cereb. Cortex 22, 455-464. doi 10.1093/cercor/bhr126

Taverna, E., and Huttner, W. B. (2010). Neural progenitor nuclei IN motion. Neuron 67 906-914. doi: 10.1016/j.neuron 2010.08.027

Toro, R., and Burnod, Y. (2005). A morphogenetic model for the development of cortical convolutions. Cereb. Cortex 15, 1900-1913. doi: 10.1093/cercor/bhi068

Toro, R., Perron, M., Pike, B., Richer L., Veillette, S., Pausova, Z., et al. (2008). Brain size and folding of the human cerebral cortex. Cereb. Cortex 18, 2352-2357. doi 10.1093/cercor/bhm261
Van Essen, D. C. (1997). A tensionbased theory of morphogenesis and compact wiring in the central nervous system. Nature $385, \quad 313-318$. doi: 10.1038/ $385313 \mathrm{a} 0$

Wang, X., Tsai, J.-W., LaMonica, B., and Kriegstein, A. R. (2011). A new subtype of progenitor cell in the mouse embryonic neocortex. Nat. Neurosci. 14, 555-561. doi: 10.1038/nn.2807

Winkler, A. M., Kochunov, P., Blangero, J., Almasy, L., Zilles, K., Fox, P. T., et al. (2010). Cortical thickness or grey matter volume? the importance of selecting the phenotype for imaging genetics studies. Neuroimage 53, 1135-1146. doi: 10.1016/j.neuroimage.2009.12.028

Xu, G., Knutsen, A. K., Dikranian, K., Kroenke, C. D., Bayly, P. V., and Taber, L. A. (2010). Axons pull on the brain, but tension does not drive cortical folding. $J$. Biomech. Eng. 132, 071013. doi: 10.1115/1.4001683

Zilles, K., Armstrong, E., Schleicher, A., and Kretschmann, H. J. (1988). The human pattern of gyrification in the cerebral cortex. Anat. Embryol. 179, 173-179. doi: 10.1007/BF00304699

Zilles, K., Palomero-Gallagher, N., and Amunts, K. (2013). Development of cortical folding during evolution and ontogeny. Trends Neurosci. 36, 275-284. doi: 10.1016/j.tins.2013.01.006

Conflict of Interest Statement: The authors declare that the research was conducted in the absence of any commercial or financial relationships that could be construed as a potential conflict of interest.

Received: 26 April 2013; accepted: 14 July 2013; published online: 01 August 2013. Citation: Lewitus E, Kelava $I$ and Huttner WB (2013) Conical expansion of the outer subventricular zone and the role of neocortical folding in evolution and development. Front. Hum. Neurosci. 7:424. doi: 10.3389/fnhum.2013.00424 Copyright (๑) 2013 Lewitus, Kelava and Huttner. This is an open-access article distributed under the terms of the Creative Commons Attribution License (CC BY). The use, distribution or reproduction in other forums is permitted, provided the original author(s) or licensor are credited and that the original publication in this journal is cited, in accordance with accepted academic practice. No use, distribution or reproduction is permitted which does not comply with these terms. 


\section{APPENDIX}

Table A1 | Neuroanatomical parameters in $\mathbf{4 0}$ mammal species*.

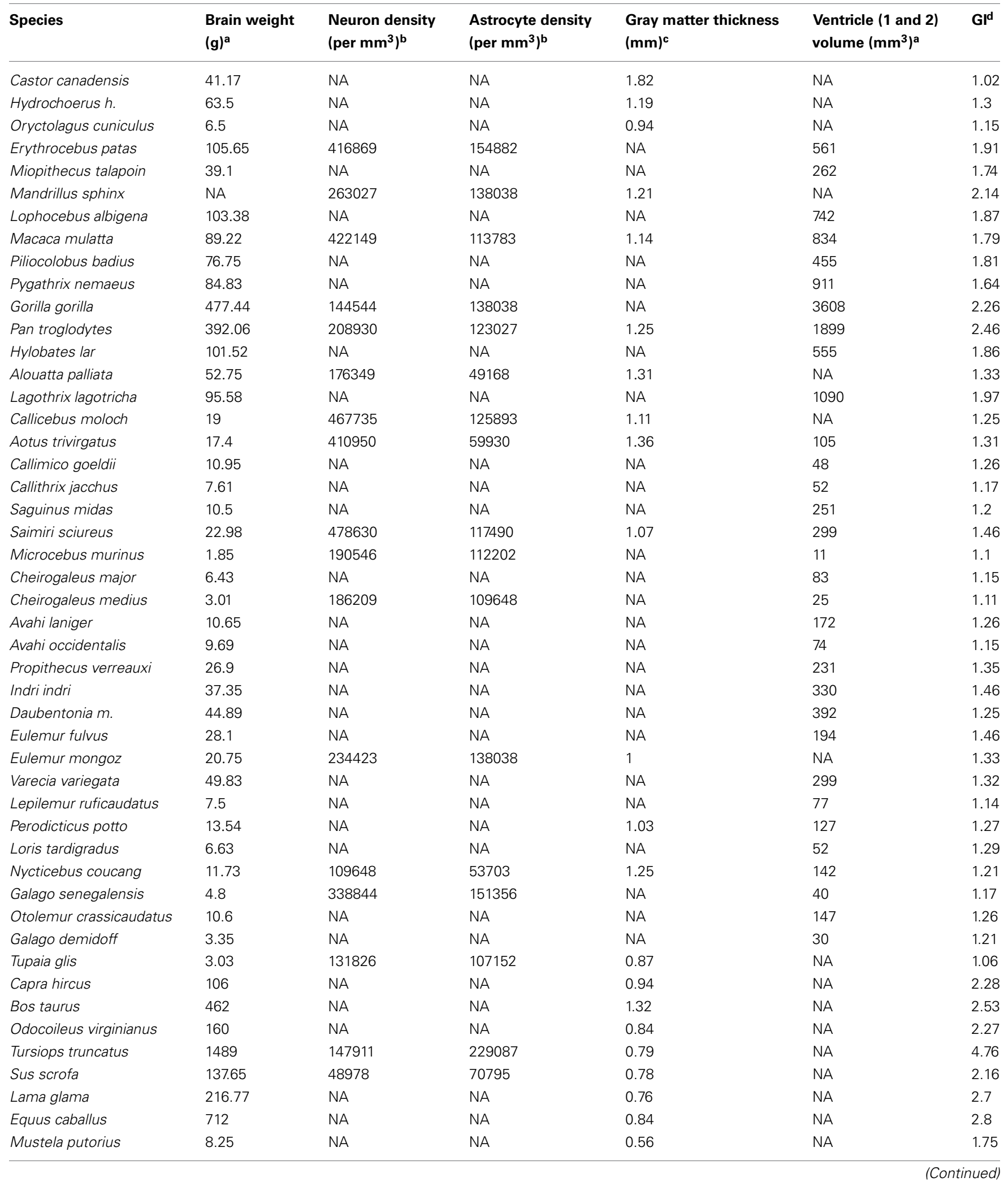


Table A1 | Continued

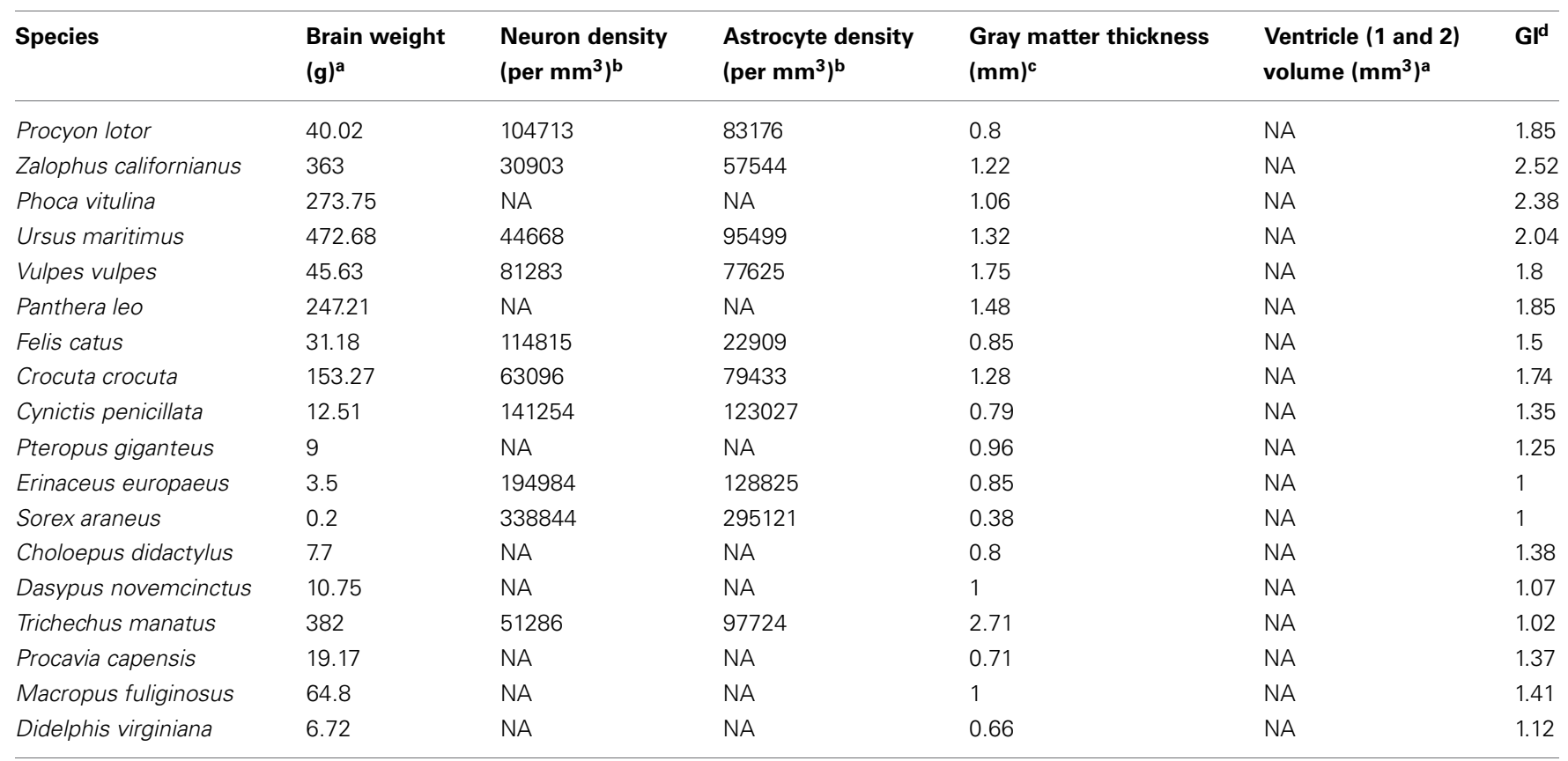

${ }^{*}$ All data for adult.

a Stephan et al., 1981.

b Lewitus et al., 2012.

c See Figure 5.

${ }^{d}$ Lewitus et al., 2013. 